\title{
A criminalização da LGBTQI+fobia no Brasil em face do abolicionismo penal
}

The LGBTQI+phobia criminalization in Brazil facing criminal abolitionism

\author{
Sofia Covas Russi \\ sofiacovas@yahoo.com.br \\ Graduada em Direito - Franca.
}

\section{Resumo}

Este artigo discute a crise do sistema penal e a criminalização da LGBTQI+fobia a partir da problematização do aumento de normas jurídicas criminais cujo propósito se convola, na prática, em um superencarceramento. Tendo como pano de fundo o abolicionismo penal, a partir do método dedutivo e de uma abordagem bibliográfica, propõe-se um acolhimento da vítima e uma resolução de conflitos que não envolva o sistema penal.

Palavras-chave: STF; criminologia crítica, resolução de conflitos, sistema penal; acolhimento da vítima.

\footnotetext{
Abstract

The article discusses the crisis in the penal system and the criminalization of LGBTQI + phobia based on the problematization of the increase in criminal legal norms whose purpose is, in practice, convoluted in a supercarceration. Against the background of criminal abolitionism, based on the deductive method and a bibliographic approach, it is proposed to welcome the victim and resolve conflicts that do not involve the penal system.

Keywords: STF; critical criminology; conflict resolution; welcoming the victim; penal system.
} 


\section{Introdução}

Em 2019, foi celebrada pelo Supremo Tribunal Federal a judicialização a favor da criminalização da homofobia, em um encaixe simbólico à Lei de Racismo (7.716/89), em um momento em que vemos, com cada vez mais frequência, um aumento do número de Leis e Emendas que tem como único e exclusivo propósito encarcerar cada vez mais pessoas. A crise do sistema penal desenvolve-se, então, entre dois pontos antagônicos: o superencarceramento e sua ineficácia. Este artigo tem por objetivo discutir a crise do sistema penal e o processo de criminalização de condutas LGBTQI+fóbicas, tendo o abolicionismo como base para a proposição de novas saídas que escapem do modelo punitivista carcerário. O trabalho emprega o método dedutivo a partir de uma abordagem bibliográfica.

\section{Abolicionismo penal: gênese, desenvolvimento e possibilidades}

O abolicionismo penal surgiu na metade do século XX, na Escandinávia, mas apenas nos anos 1970 seu coro ganhou mais força dentro das Universidades. Falar de abolição é falar de rompimento, de extinção de uma determinada prática ou instituição. O movimento é tanto social quanto teórico, negando a legitimidade da prisão e do sistema penal contemporâneo e suas formas de castigo como a resolução de conflitos. O abolicionismo penal surgiu como uma proposta racional para sua substituição, não por outro direito penal, mas por qualquer coisa melhor (BARATTA, 2011). O movimento tem grandes nomes em sua alçada, como Michel Foucault, Angela Davis, Alessandro Baratta, Eugenio Raul Zaffaroni e Louk Hulsman.

O abolicionismo não se volta apenas contra o sistema prisional, mas contra toda a esfera de justiça penal. Essa justiça é a mesma que legitima e reafirma toda violência perpetuada pelo sistema judicial e por toda uma mentalidade social. Conforme coloca Zaffaroni:

O abolicionismo nega a legitimidade do sistema penal tal como atua na realidade social contemporânea e, como princípio geral, nega a legitimação de qualquer outro sistema penal que se possa imaginar no futuro como alternativa a modelos formais e abstratos de solução de conflitos, postulando a abolição radical dos sistemas penais e a solução dos conflitos por instâncias ou mecanismos informais. (2014, p.89)

Contudo ainda nos encontramos estagnados no fato que construir mais prisões cria a falsa sensação que os direitos e deveres dos cidadãos estão seguros. Porém, a construção de 
prisões só é uma solução geográfica para problemas socioeconômicos, como coloca Ruth Gilmore (1998). Nos dias atuais, o Brasil passa por um momento em que leis penais de cunho simbólico são cada vez mais elaboradas pelo legislador infraconstitucional. No rigoroso direito penal simbólico, essas leis, de acordo com a jurista Ada Pellegrini Grinover , "trazem uma forte carga moral e emocional, revelando uma manifesta intenção pelo Governo de manipulação da opinião pública, ou seja, tem o legislador infundindo perante a sociedade uma falsa ideia de segurança" (1978, p.58).

Ou seja, o fenômeno em que se materializam ações meramente retóricas por parte do Estado em relação ao combate à criminalidade a fim de maquiar os interesses sociais. Desta maneira, como então se imaginar em uma realidade na qual o sistema prisional não existe, mas que ainda é inundada por crimes e vítimas que são afligidas por eles? Pensemos então: há um aumento exponencial de encarceramento de 7,5\% ao ano ${ }^{1}$ (BRASIL,2016) mas, mesmo encarcerando essas pessoas "desviantes" da conduta social, a criminalidade e a violência permanecem crescendo da mesma maneira. Como descreve Lucas Villa:

Cria-se, então, um estereótipo de criminoso que é difundido maciçamente entre o imaginário coletivo, etiquetando como o delinquente potencial, em geral, os homens jovens vindos de classes sociais mais carentes (pobres), ligados a grupos étnicos historicamente "desempoderados" (negros, por exemplo) e fora dos padrões estéticos dominantes (feios). (2018, p.7)

Como é colocado por Hulsman (1986), o sistema criminal surge como um mecanismo que dificulta o desenvolvimento de estratégias capazes de impactar as estruturas sociais e a maneira como as pessoas lidam com os problemas de forma a permitir o crescimento e o aprendizado e, consequentemente, evitar o processo de alienação ${ }^{2}$. Deste modo, entende-se que os sistemas penal e prisional abrem brechas que dificultam realizar o real bem para a vítima e questionam a eficiência do aprisionamento como resolução do problema sistêmico de violência. Segundo Hulsman e Van Swaaningen (2005, p.289), essa posição possibilita o desenvolvimento de uma noção de crime como uma concepção individualista, sem que isso leve em consideração a existência de uma estrutura analítica que serve de gancho para uma visão mais ampla sobre as situações problemáticas.

\footnotetext{
${ }^{1} \mathrm{O}$ total de pessoas encarceradas no Brasil chegou a 726.712 em junho de 2016 . Em dezembro de 2014, era de 622.202. Houve um crescimento de mais de 104 mil pessoas. (BRASIL, 2016).

2 De acordo com Louk Hulsman (1986,p.73), "the involvement of criminal legal systems is also described as hindering the development of strategies to act upon societal structures in such a way that people can cope and deal with problems, in a way which permits growth and learning and avoids alienation".
} 
Nesse viés de abolicionismos, Saleh-Hanna (2000) insere a necessidade de uma comunidade se empoderar sozinha e, com seus próprios termos, resolver seus problemas. Assim, critérios como hospitalidade, empatia, responsabilidade, empoderamento, compensação e outros se tornam noções basilares para atuações alternativas em termos de justiça, de forma a negar a necessidade de responder pelos prejuízos sociais tão somente a partir da prisão ou por qualquer forma de sanção retributiva ou aflitiva (CARRIER; PICHÉ, 2015).

Conforme Andrade, o abolicionismo não significa somente o fim do sistema penal, mas também da visão que ele é a resolução de conflitos sociais:

\begin{abstract}
Ainda que a abolição reconheça níveis macro e micro mais ou menos acentuados nos diferentes abolicionistas por valorizarem a dimensão comunicacional e simbólica do sistema penal, estão de acordo em que abolição não significa pura e simplesmente abolir as instituições formais de controle, mas abolir a cultura punitiva, superar a organização "cultural" e ideológica do sistema penal, a começar pela própria linguagem e pelo conteúdo das categorias estereotipadas e estigmatizantes (crime, autor, vítima, criminoso, criminalidade, gravidade, periculosidade, política criminal etc.), que tecem, cotidianamente, o fio dessa organização (pois tem plena consciência de que de nada adianta criar novas instituições ou travestir novas categorias cognitivas com conteúdos punitivos). (2006, p.172)
\end{abstract}

Os abolicionistas validam muitas táticas, intra e extrassistêmicas, desde processos de descriminalização legal, judicial, ministerial, despenalização, transferência de conflitos para outros campos do direito, como civil e administrativo, modelos conciliatórios (mediação penal de conflitos, conciliação cara a cara), terapêuticos, indenizatórios, pedagógicos (ANDRADE, 2006).

Destarte, sobre o ponto de vista abolicionista, o caminho da Criminologia Crítica não é somente mais eficiente em termos de como lidar com a criminalidade, mas também tem uma forma muito mais abrangente e restauradora de lidar com a vítima e fazê-la sentir-se realmente compreendida. É essencial pontuar que a pauta abolicionista também caminha com a pessoa afetada até o final de sua superação com o evento em que foi envolvida.

\title{
O Judiciário e as minorias: os precedentes do racismo e da violência contra
} a mulher

Primeiramente, faz-se necessário entender o que são as minorias. Minorias sociais são definidas como grupos marginalizados dentro de uma sociedade devido a aspectos econômicos, sociais, culturais, físicos ou religiosos, de gênero ou orientação sexual. 
Enquanto a igualdade formal discorre sobre a necessidade de impedir que o Estado promova toda sorte de tratamento discriminatório, a igualdade material suplica, por meio de políticas públicas e leis, que se atentem para especialidades de determinados grupos. A concepção de igualdade pede a exigência de ambas para uma construção de Estado mais justa. Tomando as palavras de Séguin, pontua-se que não é possível igualdade absoluta, tornando-se uma "utopia, uma ilusão, somente ocorre no nível imaginário. As pessoas são diferentes e devem ser tratadas de formas distintas para minimizar as desigualdades e o binômio odioso exploração/dominação" (apud PINHO, 2005, p.107).

Todavia, o olhar para leis e decretos já em vigor no sistema judicial brasileiro que abarcam o combate ao ódio direcionado a essas minorias se faz de extrema importância, pois só assim é possível, de forma mais pontual, observar as plausíveis repercussões futuras da criminalização da LGBTQI+fobia.

Primeiramente, a Lei do Racismo ( $\mathrm{n}^{\circ}$ 7.716/89) prevê crimes de discriminação ou preconceito por raça, cor, etnia, religião e procedência nacional, com pena de um a três anos, com multa. Já no Código Penal (CP), no capítulo de crimes contra a honra, o crime de injúria é descrito no art.140 como o ato de injuriar alguém, ofendendo-lhe a dignidade ou o decoro. No mesmo dispositivo, especificamente no terceiro parágrafo, é tipificado o delito de injúria por preconceito, que se refere ao emprego de elementos que digam respeito à raça, cor, etnia, religião, origem ou condição de pessoa idosa ou com deficiência. Essa modalidade é apenada de forma mais rígida, com reclusão de um a três anos e multa.

A partir de uma visão puramente dogmática, a injúria consiste em uma ofensa contra pessoa única, custando-lhe o decoro e a percepção que ela tem de si mesma, caracterizando a chamada ofensa à honra subjetiva. Por outro lado, o racismo se refere à discriminação que tem por objeto ou alvo um grupo inteiro de pessoas, ainda que a vítima imediatamente lesada seja apenas uma.

Sobre o tema, Gislene Aparecida dos Santos (2015) afirma que, para os inquéritos policiais decorrentes de crimes contra a honra, observa-se a enorme quantidade de arquivamentos em razão da decadência do prazo para realizar a queixa-crime, que era de seis meses para os crimes cometidos anteriormente a $2009 .{ }^{3}$ De acordo com a autora:

\footnotetext{
${ }^{3}$ Nem sempre era de conhecimento das vítimas que $o$ ato de comparecerem às delegacias não era suficiente para dar início a seus processos, ou seja, além disso, deveriam contratar advogados para realizar a queixa-crime.
} 
(...) entre os processos, observa-se um misto entre a desclassificação do crime de racismo tornando-o injúria racial, a decadência desses em razão da extinção do prazo para propor a queixa-crime e, também, a rejeição das denúncias por falta de provas que fossem consideradas consistentes. Ou seja, mesmo quando se admitia que os fatos eram suficientes para preencherem o tipo penal de injúria qualificada por preconceito ou racismo, em análises posteriores, verificava-se a inexistência de provas materiais do fato ou, ainda, recaíam em questões procedimentais que impediam o seguimento do processo. Sendo assim, quer por questões procedimentais (a ausência de queixa-crime no prazo previsto por lei) quer por avaliação da inexistência de mérito para denúncia (ausência de provas materiais do dolo), constatamos que a maioria dos casos foram encerrados e arquivados sem julgamento por não ter sido possível configurar a existência de qualquer crime. (SANTOS, 2015, p.191-2)

Desses processos, uma pequena porcentagem foi julgada e recebeu sentença condenatória. Isso significa que a maioria dos inquéritos policiais que veiculam registros de racismo ou injúria foram encerrados ainda durante a fase de investigação (SANTOS,2015). Monteiro (2003) observou que esse fenômeno também ganha espaço nos procedimentos do Disque Racismo no Rio de Janeiro ${ }^{4}$. Segundo coloca, práticas discriminatórias se transformam, a partir dos olhares acríticos dos magistrados, em meras discussões impelidas pelas emoções dos participantes ou verdadeiras brigas de vizinhança ${ }^{5}$. Dessa forma, o delito de racismo restava descaracterizado mesmo que a norma jurídica incriminadora preveja que, mesmo em situações desse calibre, deve haver imputação criminal como injúria racial ou racismo.

Outro importante paradigma que pode ser encontrado na relação entre as práticas judiciárias e a tutela jurídica das minorias diz respeito ao recorte do feminicídio e à(s) violência(s) contra a mulher. Essencialmente, feminicídio é o ato homicida que é cometido contra a mulher por razões da condição de sexo feminino ou em situação de estrutural violência doméstica. O Atlas da Violência (2018) indica que, no ano de 2016, mais de quatro mil e seiscentas mulheres foram assassinadas no Brasil, o que representa uma taxa de 4,5 homicídios para cada 100 mil brasileiras. Além disso, em dez anos, observou-se um aumento de $6,4 \%$.

Trata-se, como pode se observar em ambos os casos, de leis penais simbólicas em que suas atuações têm pouca ou quase nenhuma eficiência sobre o problema em si. A crítica desnudaria a seletividade na construção dos fatos jurídicos de acordo com um discurso sobre a

\footnotetext{
${ }^{4}$ Monteiro (2003) avaliou exatas 1267 ligações feitas ao Disque Racismo no Rio de Janeiro. A partir desse dado, considerou as seguintes variações: 838 eram denúncias; 572 foram indicadas para serem analisadas pela equipe técnica do Disque Racismo; 320 pessoas compareceram para a entrevista; 106 foram acolhidas como passíveis de tramitação pelo Judiciário.

${ }^{5} \mathrm{Em}$ importante estudo, Frosh (2011) analisa o quanto a cor da pele do vizinho pode ser um fator perturbador, inclusive a ponto de ser recebido como uma ameaça à identidade e como gerador de ansiedade.
} 
brasilidade, formulado em torno da ideia da cordialidade do homem brasileiro, da harmonia, da inexistência de qualquer forma de discriminação e do horror ao preconceito e ao racismo; um discurso que exalta as qualidades do povo brasileiro como ordeiro, humano, bondoso, solidário, amigo (CARVALHO,1998), mas que, simultaneamente, valoriza que cada um permaneça em seu lugar sem questionar as hierarquias raciais e sociais existentes.

Em uma sociedade que atua cada vez mais em conformidade com a lógica penalizante, a tutela das minorias e dos grupos vulnerabilizados passa a acontecer essencialmente por meio do depósito de confiança no direito penal como política pública. Essa dimensão fornece não apenas o aumento expressivo das normas jurídicas incriminadoras, mas também carrega à sociedade uma falsa impressão de segurança, proteção e enfrentamento dos problemas criminológicos.

\section{Abolicionismo penal como possibilidade para a comunidade LGBTQI+}

Em fevereiro de 2019, por oito votos a três, foi aprovada pelo Supremo Tribunal Federal (STF) a criminalização da homofobia, de modo que os crimes de ódio praticados contra a população LGBT devem ser punidos por meio da Lei do Racismo que, em sua redação original, jamais contemplou tal possibilidade. A decisão se deu a partir do ajuizamento de uma ação direta de constitucionalidade por omissão e de um mandado de injunção, responsável por romper com as lacunas da legislação constitucional. Nesse viés, argumentou-se que o próprio STF possui entendimento no sentido de que motivações de raça englobam quaisquer ideologias que tenham por condão minimizar um grupo social em detrimento de outro.

Tendo como base tais premissas, a partir de uma primeira percepção, a inclusão dos delitos de ódio contra a população LGBT no âmbito da legislação que pune os crimes de racismo seria tão somente mais uma medida de simbolismo penal. É preciso refletir em como um Judiciário punitivista estaria realmente amparando as vítimas de violência LGBTfóbica. Como coloca Luciana Costa Fernandes:

Pensar sobre a complexa matriz cultural a partir da qual se estrutura a LGBTQI+fobia nos leva a questionar se o mero cumprimento de uma pena aflitiva poderia, de fato, promover uma alteração dessa ordem. Em que medida o poder de punir tem potencial para transformar o domínio do cis sexismo, que é base das ameaças aqui tratadas? Se os altos índices das violências se devem a estruturas anteriores, e que dizem respeito à reflexão sobre a "heteronormatividade" compulsória, reivindicações pela igualdade que continuam a crer no Direito Penal como capaz de romper com essa ordem são, para dizer o mínimo, ingênuas. (2019, p.2) 
Além das críticas sobre a infundada inclusão desses delitos em lei que naturalmente não os contempla, discute-se também o fato de que as práticas de ódio podem ser enquadradas em leis gerais ou específicas de direito penal. Logo, se não foi possível obter uma resposta satisfatória capaz de reduzir o número de ocorrências de ódio contra a população LGBT, pode-se perceber que a verdadeira dificuldade não está no campo puramente normativo, mas sim no aspecto prático, das estruturas cis sexistas do sistema de justiça penal que são encarregados pela investigação e instrução processual (FERNANDES, 2019).

Nota-se ainda que há uma incongruência entre as políticas e ações que são pensadas para a defesa social da população LGBT e a realidade. Isso porque as demandas que pensam a partir da ótica da criminalização são responsáveis por negociar com um sistema historicamente construído a partir da perspectiva das dominações, exclusões concretas e violências contra a população LGBT (FERNANDES, 2019). A resposta abolicionista seria, então, uma solidariedade. Não se coloca uma solidariedade natural, algo a ser descoberto em si, e sim criado.

O abolicionismo penal, como tão enfaticamente sustentava Hulsman, é mais que uma postura teórica, é um estilo de vida que atinge positivamente as minorias em um estado policialesco e penalizante:

\begin{abstract}
Neste sentido, a justiça criminal existe em quase todos nós, assim como em algumas áreas do planeta o "preconceito de gênero" e o "preconceito racial" existem em quase todos. A abolição é, assim, em primeiro lugar, a abolição da justiça criminal em nós mesmos: mudar percepções, atitudes e comportamentos. Tal mudança causa uma mudança na linguagem e, por outro lado, uma mudança na linguagem pode ser um veículo poderoso para causar mudanças em percepções e atitudes. (2003, p.203-4)
\end{abstract}

Em sua proposta abolicionista, Hulsman (2003) apresenta significativas mudanças, como o abandono do termo "crime", que remete ao seu conceito legal, para o uso da noção de "situação-problema", com a finalidade de deixar a interpretação em aberto aos envolvidos e interessados. De acordo com esse modelo, as palavras e conceitos possuem relevância nos contextos sociais, de modo que determinados usos no campo da criminologia, da sociologia criminal e das ciências criminais como um todo estão "desagradavelmente ligadas aos conceitos discriminatórios e inconscientemente aceitos do sistema penal" (HULSMAN; CELIS, 1993, p.95).

Além disso, o sistema penal instrumentaliza a vítima. Conforme Gustavo Noronha Ávila (2017), muitas vezes é preciso que a vítima tenha muito mais suporte emocional, por exemplo, do que uma punição imposta ao seu algoz. A aposta abolicionista de Hulsman DIGNIDADE RE-VISTA | ISSN2525-698X| 2020 | V. V | N. 10 | Um olhar para a Amazônia: riquezas e diversidades | Sessão livre. Pastoral Universitária Anchieta PUC-RIO. 
(2003) é nas estruturas das justiças civil e administrativa como alternativas à justiça penal, de modo que estas disposições teriam melhores condições de promover o apaziguamento entre indivíduos, ao passo que possibilitariam à vítima e ao imputado uma resolução do conflito ocorrido face a face, através da comunicação.

A exclusão das partes, sobretudo da vítima, foi tratada por Nils Christie, ao afirmar que "a vítima em um caso criminal é uma espécie de perdedor em dobro na nossa sociedade" (2014, p.122). Para um novo modelo, seria preciso abdicar da ideia de restrição de liberdade para que assumam o centro do conflito, como forma de resposta, a reparação ou indenização do dano causado (CARVALHO,2013). A doutrina abolicionista sempre se apresenta acompanhada de algum tipo de projeto, como propõe Gabriel Ignacio Anitua:

Sua proposta de "desconstruir a definição de crime" estava naturalmente ligada ao desejo de resolver "problemas sociais". Nesse sentido, é possível deslegitimar como falsa a acusação feita aos abolicionistas em geral, e a Hulsman em particular, por fazer "utopias" e esquecer aqueles que realmente sofrem ou esquecem a realidade dos "crimes"6. (2005, p.433).

Caberia a nós mesmos, como corpo social, a eliminação da justiça penal e do empoderamento da vítima lesada, seja a lesão como for. Apesar de parecer distante da realidade, a Justiça Restaurativa, um dos componentes que pode agregar o abolicionismo penal, por exemplo, já tem diversos projetos em todo Brasil. Um modelo para a comunidade LGBTQI+ no Brasil, o vereador David Miranda apresentou o Projeto de Lei nº.5096/19, que dispõe sobre a proteção de pessoas em situação de violência baseada na orientação sexual, identidade de gênero, expressão de gênero ou características biológicas ou sexuais.

Para os interesses e necessidades concretas das vítimas, o abolicionismo recusa a lógica consumista do sistema criminal legal que cada vez mais tenta incluir vítimas em várias decisões, notavelmente aquelas sobre a aplicação correta de dor (RUGGIERO, 2010, p.1869). Mathiesen (2000) propõe substituir a obsessão com o correto ajuste de punição ao crime com uma nova obsessão, com um correto nível de ajuda e suporte para a vítima.

Ao tratar de um grupo socialmente marginalizado ao longo de dezenas de anos, o meio abolicionista abraça a causa LGBT de forma orgânica e pretende somente encaminhar a vítima para a solução mais organizada, empoderadora e solidária, em que a criminologia

\footnotetext{
${ }^{6} \mathrm{Na}$ obra original, em espanhol, Anitua escreve: Su propuesta de "deconstruir la definición de delito" iba naturalmente unida a un deseo de resolución de "problemas sociales". En este sentido es posible deslegitimar por falsa aquella imputación hecha a los abolicionistas en general, y a Hulsman en particular, por plantear "utopías" y olvidar a los que realmente sufren u olvidar la realidad de los "delitos".
} 
clássica e a recente decisão fornecida pelo STF, apesar da falsa sensação de segurança, não provêm nenhum resguardo para qualquer pessoa da comunidade LGBT.

\section{Considerações finais}

É claramente passível compreender-se, historicamente retomando leis que envolvem a proteção de minorias, que a criminologia clássica é ineficaz, quiçá até prejudicial para a vítima e sua recuperação. A criminalização da LGBTQI+fobia demonstra-se, perante parte da sociedade que a assiste com um olhar crítico e com o temor relacionado às suas perspectivas e consequências, uma maneira desesperada da morosa e sufocada justiça brasileira e de um poder legislativo alienado e ineficaz em tratar diversos problemas sociais, ao tentar abafar as discussões relativas ao tema, uma tentativa de tapar uma cratera social com uma medida "meramente ilustrativa", dado que a lei em que se enquadra já vem decepcionando por sua ineficácia prática em diversos casos.

A prática abolicionista, apresenta-se como um meio atualmente aplicável para abordar adequadamente o crime e suas ramificações, reparando o trauma moral ou físico da vítima, principalmente no que se refere às alternativas de segurança e bem-estar da vítima LGBT. Faz com que o infrator realize uma responsabilização espontânea, diferente da Justiça Clássica que pune com ares de vingança respondendo de forma improfícua, tanto ao crime, quanto ao apelo ao apoio da vítima.

Sendo assim, fica transparente o quanto os caminhos que não seguem a linha penalista do Direito têm mais chances de obter êxito, tanto no auxílio à vítima, como em responsabilizar e posteriormente reintegrar o infrator à sociedade. Por mais contraintuitivo que pareça buscar justiça em um cenário sem cárcere ou penalização, este é o caminho mais capaz de garantir toda segurança e respeito a comunidade LGBT, além de ser o único caminho em que discussões e inovações no auxílio as vítimas, na reintegração social dos infratores e apoio social podem efetivamente serem positivados e realizados na sociedade como um todo, garantido uma real mudança para uma sociedade mais próspera. 


\section{Referências bibliográficas}

ANDRADE, V. Minimalismos, abolicionismos e eficienticismo: a crise do sistema penal entre a deslegitimação e a expansão. Sequência - Estudos Jurídicos e Políticos, v.27, n.52, 2006.

Pelas mãos da criminologia: o controle penal para além da desilusão. Rio de Janeiro: Revan, 2012.

ANITUA, G. Historias de los pensamientos criminológicos. Buenos Aires: Del Puerto, 2005.

AVILA, G.; GUILHERME, V. Abolicionismos penais. Belo Horizonte: D’Plácido, 2017.

BARATTA, A. Criminologia crítica e crítica do direito penal. Rio de Janeiro: Revan, 2011.

BELUSO, O.; DUTRA, L. Abolicionismo penal desde a margem: pensando além do centro. Revista Eletrônica de Direito Penal e Política Criminal, v.5, n.1, 2017.

BRASIL. Ministério da Justiça. Levantamento Nacional de Informações Penitenciárias (Infopen): junho de 2016. Brasília: Departamento Penitenciário Nacional, 2016.

CARVALHO, S. Antimanual de criminologia. 5.ed. São Paulo: Saraiva, 2013.

CARVALHO, J. O motivo edênico no imaginário social brasileiro. Revista Brasileira de Ciências Sociais, São Paulo, v.13, n.38, p 63-79, 1998.

CASEIRO, D. É possível ser contra a criminalização homotransfobia e a favor dos direitos LGBTI+?. Justificando, 2019. Disponível em: https://www.justificando.com/2019/02/15/epossivel-ser-contra-a-criminalizacao-da-homofobia-e-a-favor-dos-direitos-lgbti/. Acesso em: 29 out 2019

CARRIER, N.; PICHÉ, J. State of abolitionism. Champ Pénal, v.12, n.1, 2015.

CHRISTIE, N. Uma razoável quantidade de crime. Trad. André Nascimento. Rio de Janeiro: Revan, 2013.

FERNANDES, C. L. Criminalização da LGBTQI+fobia no Brasil pós-democrático: possíveis discussões a partir da crítica criminológica. Boletim IBCCrim, n.322, set 2019.

FROSH, Stephen. The relational ethics of conflict and identity. Psychoanalysis, Culture \& Society, n.16, p.225-43, 2011.

GILMORE, R. Globalisation and U.S prison growth: from military Keynesianism to postKeynesian militarism. Race and Class, v.40, n.2/3, out 1998.

GRINOVER, A. P. Eficácia e autoridade da sentença penal. São Paulo: Revista dos Tribunais, 1978. 
GOÉS, Luciano. Abolicionismo penal? Mas qual abolicionismo, "cara pálida"? Revista InSURgência, Brasília, v.3, n.2, 2017.

HULSMAN, L. Critical criminology and the concept of crime. Contemporary Crises, v.10, n.1, p.63-80, 1986.

HULSMAN, L. Une perspective abolitionniste du système de la justice pénale et un schéma d'approche des situations problématiques. In: DEBUYST, C. (Coord.). Dangerosité et justice pénale: ambiguité d'une pratique. Genève: Masson-Médecine et Hygiène, 1981.

HULSMAN, L. CELIS, J. B. Penas perdidas: o sistema penal em questão. Trad. Maria Lúcia Karan. Rio de Janeiro: Luam, 1993.

HULSMAN, L. Temas e conceitos numa abordagem abolicionista da justiça criminal. Verve Revista Semestral Autogestionária do Nu-Sol, v.1, n. 3, p.190-210, 2003.

INCOTT, P. Precisamos conversar sobre o abolicionismo penal. Justificando, 2017. Disponível em: http://www.justificando.com/2017/01/19/precisamos-conversar-sobreabolicionismo-penal/. Acesso em: 21 out 2019.

MATHIESEN, T. Towards the 21st century: abolition, an impossible dream? Humanity and Society, v.22, n.1, p.4-22, 2000.

MONTEIRO, F. D. Retratos em branco e preto, retratos sem nenhuma cor: a experiência do disque-racismo da Secretaria da Segurança Pública do Estado do Rio de Janeiro. 2003. Dissertação (Mestrado em Sociologia) - Programa de Pós-Graduação em Sociologia e Antropologia, Universidade Federal do Rio de Janeiro, 2003.

PINHO, L. O. Princípio da igualdade: investigação na perspectiva de gênero. Porto Alegre: Sérgio Antônio Fabris, 2005.

RUGGIERO, V. Penal abolitionism. New York: Oxford University Press, 2010.

SANTOS, G. Nem crime, nem castigo: o racismo na percepção do judiciário e das vítimas de atos de discriminação. Revista do Instituto de Estudos Brasileiros, n.62, p.184-2017, dez 2015.

SALEH-HANNA, V. Taking too much for granted: studying the movement and re-assessing the terms. In: WEST, W. G..; MORRIS, R. (Orgs.). The case of penal abolition. Toronto: Canadian Scholars' Press, 2000.

VAN SWAANINGEN, R. Public Safety and the Management of Fear. Theoretical Criminology, v.9, n.3, p.289-305, 2005.

VILLA, L. Gozo punitivo, gozo panóptico e abolicionismo penal: redescrevendo a prática de enjaular seres humanos a partir da filosofia e da psicanálise. Revista Natureza Humana, São Paulo, v.20, n.1, p.188-222, jan/jul 2018. 
RUSSI, Sofia Covas. A criminalização da LGBTQI+fobia no Brasil em face do abolicionismo penal.

Dignidade Re-Vista, v.6, n.10, julho 2020

\section{DIGNIDADE \\ RE.VISTA}

ZAFFARONI, E. R. Em busca das penas perdidas: a perda da legitimidade do sistema penal. 5.ed. Rio de Janeiro: Revan, 2014. 